BMJ Open

Sport \&

Exercise

Medicine

\title{
Does the new rugby union scrum sequence positively influence the hooker's in situ spinal kinematics?
}

\author{
Ramesh Swaminathan, ${ }^{1}$ Jonathan M Williams, ${ }^{2}$ Michael D Jones, ${ }^{1}$ \\ Peter S Theobald ${ }^{1}$
}

To cite: Swaminathan $\mathrm{R}$, Williams JM, Jones MD, et al. Does the new rugby union scrum sequence positively influence the hooker's in situ spinal kinematics?. BMJ Open Sport Exerc Med 2016;2:e000064. doi:10.1136/bmjsem-2015000064

- Prepublication history for this paper is available online. To view these files please visit the journal online (http://dx.doi.org/10.1136/ bmjsem-2015-000064).

Accepted 1 January 2016

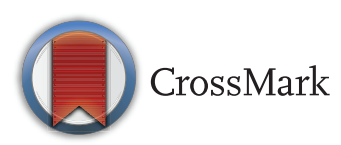

${ }^{1}$ Bioengineering Research Group, School of Engineering, Cardiff University, Cardiff, South Glamorgan, UK

${ }^{2}$ Faculty of Health and Social Sciences, Bournemouth University, Bournemouth, Dorset, UK

Correspondence to Dr Peter S Theobald; TheobaldPS@Cardiff.ac.uk

\section{ABSTRACT}

Background: Scrummaging is unique to rugby union and involves 2 'packs' of 8 players competing to regain ball possession. Intending to serve as a quick and safe method to restart the game, injury prevalence during scrummaging necessitates further evaluation of this environment.

Aims: The aim of this study was to determine the effect of scrummage engagement sequences on spinal kinematics of the hooker. The conditions investigated were: (1) live competitive scrummaging using the new 'crouch, bind, set' sequence; (2) live competitive scrummaging using the old 'crouch touch pause engage' sequence and (3) training scrummaging using a scrum machine.

Methods: Inertial sensors provided three-dimensional kinematic data across 5 spinal regions. Participants $(n=29)$ were adult, male community club and universitylevel hookers.

Results: Engagement sequence had no effect on resultant kinematics of any spinal region. Machine scrummaging resulted in lesser magnitudes of motion in the upper spinal regions. Around two-thirds of the total available cervical motion was utilised during live scrummaging.

Conclusions: This study indicates that the most recent laws do not influence the spinal kinematics of the hooker during live scrummaging; however, there may be other benefits from these law changes that fall outside the scope of this investigation.

\section{INTRODUCTION}

Rugby union players are consistently exposed to a relatively high risk of injury across all playing levels. ${ }^{1-12}$ While the high level of participation suggests that players accept this risk of injury, specific elements within the game remain the target for reduction strategies. The scrummage (hereafter termed the 'scrum'), involves eight players from each team attempting, en masse, to push their opponents backwards and regain ball possession. This represents the contact event with the highest risk of injury within the sport. ${ }^{13}$ World Rugby,

\section{What are the new findings?}

- There are no spinal kinematic differences between the two competitive scrummaging scenarios indicating neither a positive nor negative effect of the law change.

- Large magnitudes of thoracic and lumbar spine motion may put these spinal regions at an increased risk of injury.

- Machine scrummaging is a much more constrained kinematic environment.

- Modest amount of cervical flexion may be owing to a large amount of 'stabilising' muscle forces in order to minimise head displacement.

the game's governing body, has recently evolved the laws in an attempt to reduce this risk of injury; hence, as of the 2013/2014 playing season, the scrum followed the referee's command 'crouch-bind-set' (CBS), as opposed to 'crouch-touch-pause-engage' (CTPE). ${ }^{14}$

Scrum injuries can be either acute, chronic or degenerative in nature, ${ }^{15-17}$ with longer term exposure to this demanding biomechanical environment associated with disc narrowing $\quad(35-71 \%$ incidence), osteophyte formation $(83 \%)$, apophyseal joint degeneration $(74 \%)$, and degeneration of the vertebral endplates (77\%). ${ }^{18}{ }^{19}$ Given the time spent scrummaging compared with other contact events during a game, it is associated with a disproportionately high percentage $(6-13 \%)$ of all spinal injuries within the sport. ${ }^{20-25}$ These spinal injuries predominantly happen to players of the front row. Front-row players (ie, the three players from each team, who directly oppose each other) are at particular risk of both chronic and acute injuries, accounting for $78 \%$ of all scrum-based acute cervical spine injuries. ${ }^{21} 26$ While it is acknowledged that risk of injury is multifactorial, the biomechanical demands of the scrum are unique and are likely to significantly contribute to the risk of injury. The 
scrum consists primarily of the 'hit/impact', followed by a sustained attempt to 'shove'. The 'hit' is where the two packs initially engage, immediately after the referee's instruction. Both packs then produce a sustained shove, aiming to push the opposition away from the ball. As the packs engage, the shoulders of the front-row players of each team collide, their heads become interlocked and are forced underneath the chest of their opposing player. The impact force of this interaction has previously been reported, varying from $4.4-16.5 \mathrm{kN},{ }^{27-31}$ measured by instrumenting either the scrum machine or shoulder pads (point of impact) of front-row players, during live scrummaging. ${ }^{31}$

Recent kinematic studies have additionally focused on investigating neuromuscular activation patterns during simulated, live and machine-based scrummaging. ${ }^{31} 32$ While no significant differences were observed between engagement sequences for body kinematics, it does appear that the 'crouch-bind-set' engagement sequence may prepare the cervical spine by stiffening the joints prior to impact. Furthermore, it was reported that machine scrummaging does not accurately replicate live scrummaging, suggesting the need for future studies to focus on investigations of live scrummaging.

As the scrum has been identified as being specifically associated with injury, a greater understanding of spinal kinematics will further aid in the quest for injury reduction. To date, while studies have considered machinebased and simulated live scrummaging, ${ }^{33} 34$ technical challenges have prevented studies from acquiring spinal kinematics during competitive scrummaging. Given the association between scrummaging and the potential for spinal injury, it is critical that these challenges are met to enable data acquisition in the most relevant physical environment.

This study aimed to determine the resultant spinal kinematics of the hooker during competitive scrummaging using two different sequences (CBS and CTPE), and using CBS when performing machine-based scrummaging. This study focused on the most injury-prone player, the hooker, ${ }^{21}{ }^{23-25}$ generating the first data sets that allow direct comparison of spinal kinematics between the new and old scrum sequences. It was hypothesised that the hooker's spinal kinematics will be more constrained during the new (CBS), as opposed to the older (CTPE), engagement sequence.

\section{MATERIALS AND METHODS}

A repeated-measures design was employed to evaluate the effect of the scrum engagement sequence (within-group factor) on three-dimensional spinal kinematics. The methodology replicated the scrum law evolution in both training and competitive scenarios.

\section{Participants}

Hookers were recruited from a convenience sample of local community club and university rugby union teams.
Data were collected from all participants during team versus team interactions (hereafter described as competitive scrummaging), using both the old and new scrum sequences. Some of these hookers were also analysed when their eight players (the 'pack') were using a scrum machine within a typical training scenario. All participants were deemed by their qualified coach to have the requisite skill and knowledge of playing in this position, and had been appropriately trained, according to World Rugby guidelines. ${ }^{14}$ Potential participants were excluded if they had inadequate front-row experience, a history of any major spinal injury, or any indication of current neuromusculoskeletal neck problems (eg, pain). The study was approved by the Cardiff School of Engineering Ethics Committee, with all volunteers providing written informed consent.

\section{Equipment}

Participants were instrumented with a string of inertial sensors (THETAMetrix, Waterlooville, UK) adhered to the skin on the forehead and overlying the spinous processes of C7, T7, T12, L3 and S1 (figure 1). Each sensor was comprised of a triaxial accelerometer, gyroscope and magnetometer, and sampled at $40 \mathrm{~Hz}$ /sensor. The

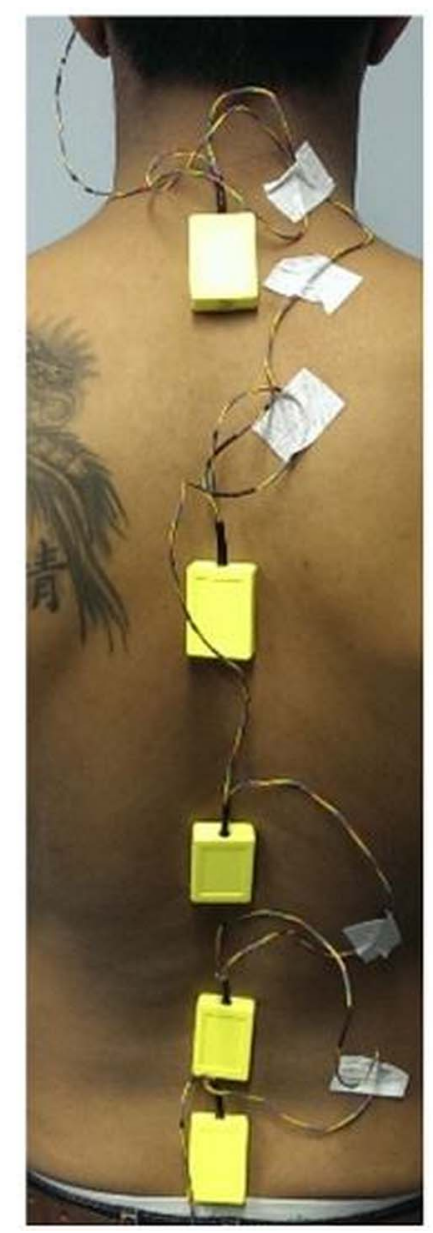

Figure 1 Inertial sensor placements over the spinous processes of C7, T7, T12, L3 and S1. 
sensors had previously been validated for reliability and accuracy during factory calibration, with errors typically $<1^{\circ}$. The sensors' fusion algorithm, incorporating Kalman filtering, provided drift-free computation of absolute orientation. Similar sensors have been widely used for spinal motion analysis, ${ }^{35} 36$ and such an experimental set has been used previously during rugby scrummaging. ${ }^{37}$ Each sensor was adhered directly to the skin using double-sided hypoallergenic tape.

This created five spinal 'segments' (ie, the spinal region between these 6 specific locations), which were defined as the cervical (C), upper thoracic (UTx), lower thoracic (LTx), upper lumbar (ULx) and lower lumbar (LLx) regions. A modified scrum cap was used to reinforce the attachment of the forehead sensor. Absolute orientations, expressed as Euler angles, were determined for each sensor and stored on a PC.

\section{Procedures}

Data collection was integrated within scheduled training sessions, such that all players were familiar with the facilities and environment. All participants completed their club's standard warm-up routine before being instrumented with the inertial sensors and taking part in their trial. Each trial lasted approximately $15 \mathrm{~min}$. Prior to scrummaging, each player completed range of motion (ROM) trials to characterise their normal, active, spinal ROM. This was performed for the full spine, while additional cervical spine ROM data was collected in a position of hip flexion (similar to that of scrummaging). Each uniplanar motion was performed three times in a predefined order (flexion/extension, lateral bending and rotation), with a short pause in between each motion. The participant always resumed a neutral position between movements. For the cervical segment, normalisation was performed from the hip flexion ROM trial. For all other segments, normalisation was performed from the standing ROM trial. The peak ROM was calculated for each motion and each spinal segment. All participants then performed three trials of the new (CBS) and old (CTPE) sequences, within a competitive environment, with scrums being performed on either grass or synthetic (3G) turf, depending on their training facilities. The sequence of scrums was randomised, with players instructed to replicate their 'in-game' scrum performance. Prior to testing, participants were assigned a value, via a table of randomised numbers, as to the order they would perform the two engagement sequences. All trials for one engagement sequence were completed before moving onto the next sequence. Players were allowed $2 \mathrm{~min}$ for full physiological recovery between each trial, ${ }^{38} 39$ to minimise the effect of fatigue. ${ }^{40}{ }^{41}$ Additionally, where a scrum machine was available, the pack also performed the CBS sequence to replicate a typical training scenario.

\section{Data processing}

Absolute orientations of the sensors, described as Euler angles, were converted to rotation matrices, and resultant angles between two adjacent sensors were calculated through matrix multiplication. This process is commonplace in three-dimensional kinematic analysis, with the resultant angles describing the ROM of each spinal segment. ROM computation was completed using custom Matlab (Mathworks, 2012a) scripts. ${ }^{35} 3742$ The rotation order corresponded to motion describing flexion-extension, lateral bending and rotation. This resulted in six motions for each spinal segment described as flexion, extension, left and right lateral bending, and left and right rotation.

$\mathrm{ROM}$ values were used to determine the spinal ROM relative to each participant's maximal ROM, defined in the earlier ROM trials, as it is increasingly acknowledged that end-range postures have the potential to increase risk of injury. ${ }^{43-46}$ Data were time-normalised according to event duration. All kinematic data were filtered using a zero lag 4th order low-pass Butterworth filter, with a $6 \mathrm{~Hz}$ cut-off frequency. ${ }^{47}$ Sensor-skin adhesion was confirmed before and after each trial, with data discounted in cases where there appeared to have been sensor displacement.

\section{Participants and environment}

Table 1 describes the 29 hookers analysed during the competitive scrum scenarios. Fourteen of these hookers were also analysed within a training scenario, with their pack scrummaging against a machine on a grass surface.

\section{Statistical analysis}

Normality and sphericity were checked using Shapiro-Wilk and Mauchly's test, respectively. A one-way repeated measures ANOVA, with scrum condition as the within-group factor (ie, competitive (CBS), competitive (CTPE), training), was applied to test for differences across the variables, with post-hoc Bonferroni comparisons where appropriate. Significance was set at $\mathrm{p}<0.05$. All tests were performed with SPSS V.22 (SPSS Inc, Chicago, USA).

\section{RESULTS}

\section{Kinematic analysis}

There were no significant differences in kinematics for any spinal region between the two engagement

Table 1 Data describing the 29 hookers analysed within a competitive scrum

\begin{tabular}{lc}
\hline Descriptor & Mean (SD) \\
\hline Age & $23.4(4.2)$ years \\
Height & $1.76(0.04) \mathrm{m}$ \\
Mass & $101.1(12.8) \mathrm{kg}$ \\
Body mass index & $32.6(4.0) \mathrm{kg} / \mathrm{m}^{2}$ \\
\hline
\end{tabular}


Table 2 Mean (SD) data describing the ROM for each sequence

\begin{tabular}{|c|c|c|c|c|}
\hline \multirow[b]{2}{*}{ Spinal region } & \multirow[b]{2}{*}{ ROM (degrees) } & \multicolumn{2}{|c|}{ Competitive $(n=29)$} & \multirow[b]{2}{*}{ Training $(n=14)$} \\
\hline & & CTPE & CBS & \\
\hline \multirow[t]{6}{*}{ Cervical } & Flexion & $16.6(10.6)$ & $18.1(9.3)$ & $11.1(8.2)$ \\
\hline & Extension & $16.9(11.2)$ & $17.8(9.9)$ & $18.2(5.5)$ \\
\hline & Right side flexion & 20.8 (11.3) & $18.5(9.8)$ & $16.1(8.7)$ \\
\hline & Left side flexion* & $19.1(13.3)^{\star}$ & $19.5(12.3)^{\star}$ & $9.9(5.3)^{\star}$ \\
\hline & Right rotation* & $24.9(10.0)^{*}$ & $20.9(9.1)$ & $14.3(9.7)^{\star}$ \\
\hline & Left rotation & $14.8(10.6)$ & $12.8(7.8)$ & $17.4(9.1)$ \\
\hline \multirow[t]{6}{*}{ Upper thoracic } & Flexion & $10.6(5.4)$ & $8.9(7.3)$ & $9.0(5.4)$ \\
\hline & Extension & $25.1(13.5)$ & $22.1(10.0)$ & $13.6(5.3)$ \\
\hline & Right side flexion & $11.4(6.8)$ & $10.6(6.2)$ & $8.3(5.0)$ \\
\hline & Left side flexion & $15.8(9.9)$ & $15.3(11.8)$ & $9.2(6.1)$ \\
\hline & Right rotation & $10.7(7.3)$ & $14.7(12.5)$ & $10.6(5.7)$ \\
\hline & Left rotation* & $21.7(10.8)^{\star}$ & $16.0(9.6)$ & $12.0(11.1)^{\star}$ \\
\hline \multirow[t]{6}{*}{ Lower thoracic } & Flexion & $5.1(5.4)$ & $4.7(6.6)$ & $4.0(4.9)$ \\
\hline & Extension & $17.4(10.3)$ & $16.0(9.0)$ & $16.1(6.3)$ \\
\hline & Right side flexion & $7.6(4.7)$ & $6.7(4.0)$ & $8.5(6.4)$ \\
\hline & Left side flexion* & $16.6(5.5)^{\star}$ & $15.3(7.4)^{*}$ & $8.0(3.8)^{*}$ \\
\hline & Right rotation & $9.9(7.2)$ & $14.0(11.6)$ & $6.8(3.7)$ \\
\hline & Left rotation & $13.2(6.8)$ & $12.0(5.8)$ & $9.4(6.5)$ \\
\hline \multirow[t]{6}{*}{ Upper lumbar } & Flexion & 43.1 (12.3) & $42.3(11.0)$ & $42.4(10.3)$ \\
\hline & Extension & $0.8(3.0)$ & $0.4(0.8)$ & $0.8(1.6)$ \\
\hline & Right side flexion & $7.9(6.0)$ & $7.2(4.8)$ & $6.9(6.1)$ \\
\hline & Left side flexion & $10.9(6.3)$ & $10.6(6.3)$ & $7.6(4.3)$ \\
\hline & Right rotation & $13.5(5.9)$ & 12.9 (7.9) & $9.7(9.9)$ \\
\hline & Left rotation & $7.7(7.4)$ & $8.0(6.8)$ & $6.4(4.6)$ \\
\hline \multirow[t]{6}{*}{ Lower lumbar } & Flexion & $14.2(12.5)$ & $16.1(17.1)$ & $11.3(12.0)$ \\
\hline & Extension & $9.8(7.4)$ & $11.6(9.1)$ & $9.9(5.6)$ \\
\hline & Right side flexion & $7.5(5.1)$ & $9.4(6.7)$ & $7.2(6.3)$ \\
\hline & Left side flexion & $8.3(6.4)$ & $10.1(9.0)$ & $7.9(6.7)$ \\
\hline & Right rotation & $12.6(10.1)$ & $10.0(10.9)$ & $10.1(8.6)$ \\
\hline & Left rotation & 11.9 (10.3) & 15.9 (12.0) & $10.0(8.7)$ \\
\hline
\end{tabular}

sequences during competitive scrummaging $(\mathrm{p}>0.05)$. Table 2 presents the mean peak motion data for the two scrum engagement sequences.

Significantly greater ROM was identified in the upper three spinal segments in both competitive sequences, versus the training (machine scrummaging) scenario. No significant differences (ie, $\mathrm{p}>0.05$ ) were evident in the two lowest spinal regions.

Data presented in figures $2 \mathrm{~A}-\mathrm{C}$ provides dynamic cervical ROM across the competitive CBS scrum scenarios, describing the flexion-extension, lateral bending and rotation left to right, respectively. Figures 2D-F describe equivalent data from the older CTPE engagement sequence. In each case, data has been time normalised and combined to yield a confidence corridor for ROM during scrummaging. The solid line represents the cohort mean and the dotted lines represent the upper and lower $95 \%$ CIs.

ROM relative to maximal ROM (figure 3) demonstrated no significant difference between scrummaging sequences $(\mathrm{p}>0.05)$. It did, however, identify that almost all available ROM was used for a number of spinal regions.

\section{DISCUSSION}

This study set out to determine whether the evolution of rugby laws relating to the scrum had any effect on hooker spinal kinematics during competitive scrums. The results presented here indicate that the changes in laws do not have any significant effect on hooker spinal kinematics when comparing between the CBS (new) and CTPE (old) scrummaging sequences. There were some kinematic differences between training and competitive scrummaging trials but only for the upper spinal regions. This study performed the first multiregional spinal analysis, generating data that enhances our understanding of spinal kinematics within both a training and competitive environment, and using the new and old scrummaging sequences.

Previous studies have demonstrated that CBS engagement has significantly influenced the biomechanics of scrummaging. ${ }^{31} 48$ Indeed, growing evidence exists that the impact of engagement is reduced using CBS, as measured by the impact to the shoulder girdle in both machine, ${ }^{49}$ and live ${ }^{48} 50$ scrummaging. This was attributed to a reduced distance between front-row players prior to the impact phase. The current study did not 

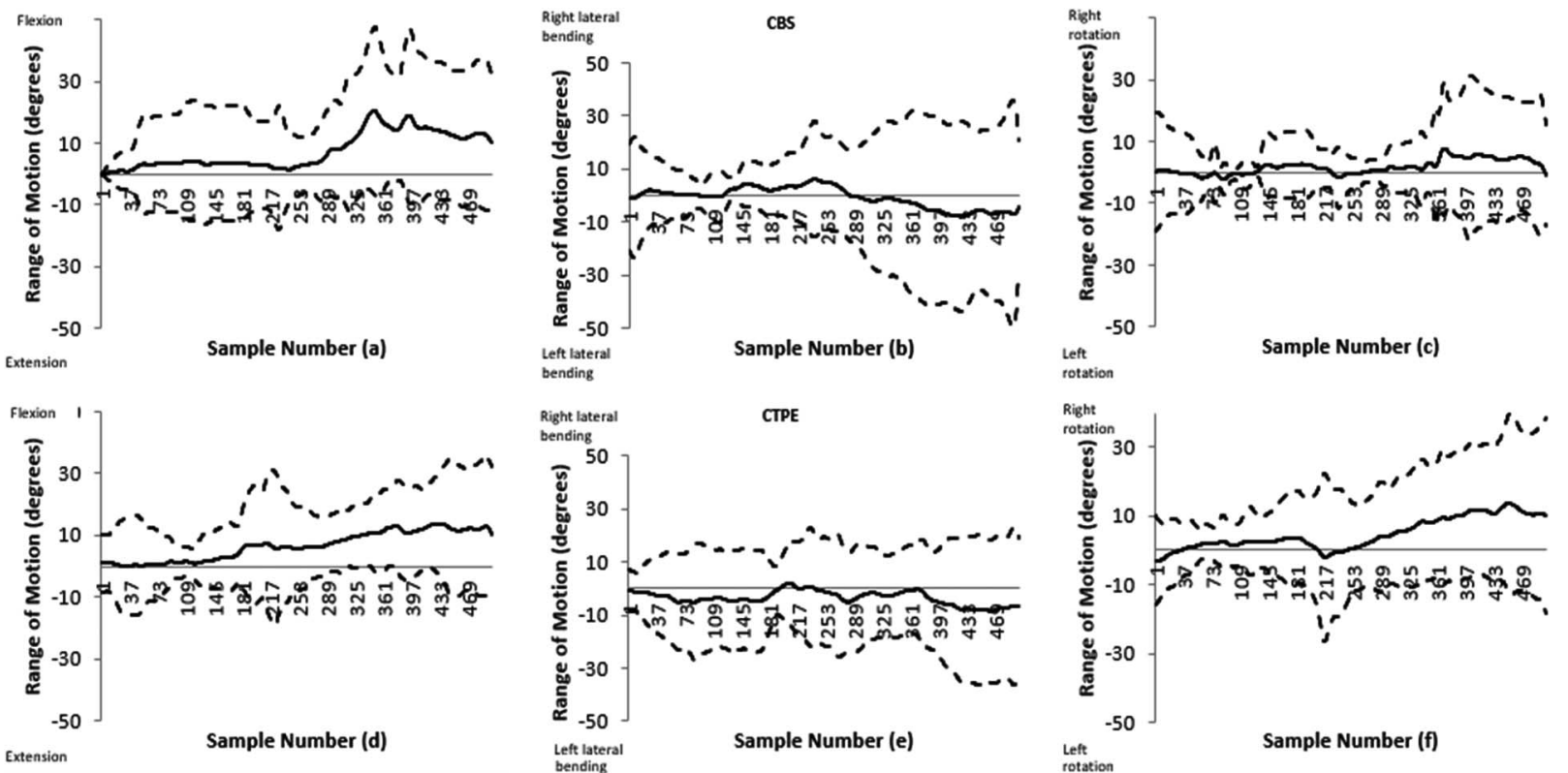

Figure 2 Dynamic cervical spine ROM during competitive (CBS and CTPE) training scrums. Solid line=mean; dashed lines= upper and lower 95\% Cl limits. CBS figures-(a: flexion/extension, b: lateral bending, c: rotation); CTPE figures-(d: flexion/ extension, e: lateral bending, f: rotation). CBS, Crouch-bind-set; CTPE, Crouch-touch-pause-engage; ROM, range of motion.

measure the impact phase specifically, nor impact at the shoulders. Instead, we sought further understanding of the law change on other biomechanical measures. To this end, the findings of the current study do not support or refute the recommendations to move to the new laws, though synthesising all available data would suggest that the new laws result in reduced shoulder impact, and do not negatively influence spinal kinematics.

The data presented in this study demonstrated no difference in spinal ROM across the scrummaging sequences. The extent of spinal motion varied across the population, and appeared to be dependent on both the participant and the nature of the scrum. The

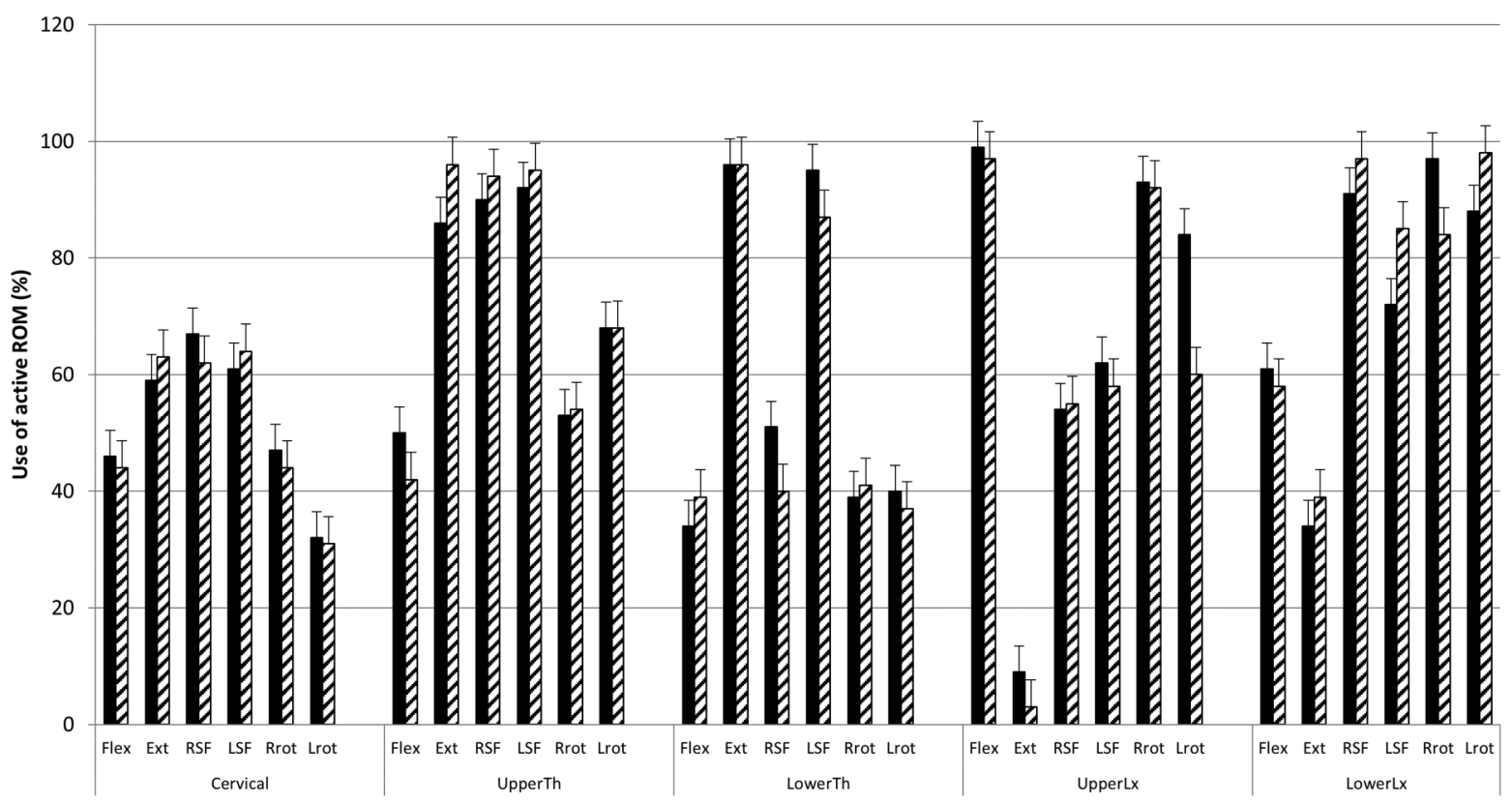

Figure 3 The relative proportion of active ROM used during competitive scrummaging per spinal region, averaged across the cohort. Black columns = CTPE; Hatched columns = CBS. Error bars represent SE. CBS, Crouch-bind-set; CTPE, Crouch-touch-pause-engage; ROM, range of motion. 
particularly large variability observed in the cervical ROM (figure 2) would indicate that intrinsic control of ROM is the main determinant of kinematics during scrummaging; hence, it could be extrapolated that spinal kinematics may not be readily influenced solely by evolving scrum laws. It is also noted that approximately $60 \%$ of total sagittal ROM was utilised during scrummaging, suggesting that both sequences (CBS and CTPE) represent a relatively low risk of hyperflexion for most participants, a mechanism believed to be linked to catastrophic injury. ${ }^{51}$ It may be that catastrophic hyperflexion injuries are the sole domain of the collapsed scrum; however, a more substantive claim can only be levied on observing a greater number of scrums.

Our data also indicated that machine scrummaging utilised significantly less ROM for the upper spinal regions, which is consistent with reports of less cervical muscle demand of machine versus live scrummaging. ${ }^{32}$ Combining this data seems to suggest that machine scrummaging requires significantly less cervical and upper thoracic ROM, and less cervical muscle activity; hence, this appears to be an environment which poorly reflects the true cervical demands of live scrummaging. Indeed, knowledge of this less-intense environment may prove a useful addition to the rehabilitation pathway following cervical injury, while also highlighting the importance of additional conditioning prior to competitive scrummaging.

Reducing chronic injury from the scrum environment is complex. Greater or excessive spinal motion is associated with chronic degeneration in all regions of the spine, ${ }^{52} 53$ thereby leading to conclusions regarding reduced ROM being beneficial for chronic injury potential. Indeed, we observed only a modest range of cervical motion ( $63 \%$ of total available range), suggesting that excessive motion may not be the main source of degenerative change in the cervical spines of front-row players. For a front-row player to constrain motion in an oppressing environment requires significant muscle activity. Such muscle activity would, of course, result in a cost of compressive load, also known to be linked to chronic degeneration. ${ }^{54}$ The relatively modest cervical ROM observed in this study may be the result of a large amount of 'stabilising' muscle forces, where the demands of the dynamic competitive scrum see the hooker attempt to minimise head displacement. To this end, the greater muscle activity noted in previous CBS studies $^{32}$ would indicate relatively high compressive loads on the cervical spine. ${ }^{54}$ This may provide some explanation as to the relationship between scrummaging and long-term degenerative changes in the cervical spine.

Scrummaging utilises a greater proportion of thoracic and lumbar spine ROM, versus cervical spine ROM. Indeed, over $90 \%$ of the available range was used during extension and lateral bending in the thoracic spine, flexion for the upper lumbar spine, and side bending and rotation for the lower lumbar spine. This is significant, as end-range spinal positions may result in reduced muscle activity, ${ }^{55}$ altered muscle function, ${ }^{56}$ increased load on the passive osteoligamentous spine, ${ }^{57}$ and increased risk of tissue damage ${ }^{46}$ Indeed, reduced tissue compliance and bony opposition associated with end-range, negatively influences the available motion in other planes; ${ }^{58}{ }^{59}$ hence, the use of such large proportions of the available range may expose the thoracic and lumbar spine to greater risk of injury. ${ }^{60}$

In performing the first multiregional spinal kinematics evaluation of the hooker within the rugby union scrum, this study is unique in presenting the greatest detail of spinal kinematic data. This analysis revealed that, when considering the relative motion of the five spinal regions, there was statistically insignificant kinematic variation between the new (CBS) and old (CTPE) sequences. This study adds to the debate surrounding scrummaging, by using novel methods to report the first spinal kinematics from within a competitive environment. Our data does not, however, support the notion that the new scrum laws will succeed in reducing chronic spinal injury.

Limitations of the current study include that it was conducted during training, which is unlikely to represent an identical biomechanical loading pattern to the more aggressive and physical nature of a competitive match. No detail regarding the specific phases of scrummaging were captured; therefore, it was not possible to relate specific ROM to specific scrum phases. Owing to the sampling frequency of data capture, it was not possible to report on the impact forces experienced at the spinal regions, although this was not the primary aim of our study.

\section{CONCLUSIONS}

Our data indicates that the scrum engagement sequence does not affect spinal kinematics of the hooker during competitive scrummaging. Machine scrummaging results in less ROM for the upper spinal regions compared to competitive scrummaging. Approximately $60 \%$ of available flexion ROM of the cervical spine was used during competitive scrummaging, whereas the lumbar spine utilised the entire ROM. Our data adds to the debate that influencing spinal kinematics within the scrum may require more drastic changes in law, owing to an individual's intrinsic control of motion.

Acknowledgements The authors would like to acknowledge all the participants who volunteered for this study without whom it would not have been possible. Furthermore, the authors would like to declare that there is no conflict of interest.

Competing interests None declared.

Ethics approval Cardiff School of Engineering Ethics Committee.

Provenance and peer review Not commissioned; externally peer reviewed.

Data sharing statement No additional data are available.

Open Access This is an Open Access article distributed in accordance with the Creative Commons Attribution Non Commercial (CC BY-NC 4.0) license, 
which permits others to distribute, remix, adapt, build upon this work noncommercially, and license their derivative works on different terms, provided the original work is properly cited and the use is non-commercial. See: http:// creativecommons.org/licenses/by-nc/4.0/

\section{REFERENCES}

1. Bleakley C, Tully M, O'Connor S. Epidemiology of adolescent rugby injuries: a systematic review. J Athl Train 2011;46:555-65.

2. Nicol A, Pollock A, Kirkwood G, et al. Rugby union injuries in Scottish schools. J Public Health (Oxf) 2011;33:256-61.

3. Palmer-Green DS, Stokes KA, Fuller CW, et al. Match injuries in English youth academy and schools rugby union: an epidemiological study. Am J Sports Med 2013;41:749-55.

4. Brooks JHM, Kemp SPT. Recent trends in rugby union injuries. Clin Sports Med 2008;27:51-73.

5. Bottini E, Poggi EJ, Luzuriaga F, et al. Incidence and nature of the most common rugby injuries sustained in Argentina (1991-1997). Br J Sports Med 2000;34:94-7.

6. Lee AJ, Garraway WM. Epidemiological comparison of injuries in school and senior club rugby. Br J Sports Med 1996;30:213-17.

7. Schick DM, Molloy MG, Wiley JP. Injuries during the 2006 Women's Rugby World Cup. Br J Sports Med 2008;42:447-51.

8. Taylor AE, Fuller CW, Molloy MG. Injury surveillance during the 2010 IRB Women's Rugby World Cup. Br J Sports Med 2011;45:1243-5.

9. Bathgate A, Best JP, Craig G, et al. A prospective study of injuries to elite Australian rugby union players. Br J Sports Med 2002;36:265-9; discussion 269.

10. Schwellnus MP, Thomson A, Derman W, et al. More than $50 \%$ of players sustained a time-loss injury ( $>1$ day of lost training or playing time) during the 2012 Super Rugby Union Tournament: a prospective cohort study of 17,340 player-hours. Br J Sports Med 2014;48:1306-15.

11. Targett SJR. Injuries in Professional Rugby Union. Clin J Sport Med 1998;8:280-5.

12. Williams S, Trewartha G, Kemp S, et al. A meta-analysis of injuries in senior men's professional Rugby Union. Sport Med 2013;43:1043-55.

13. Fuller CW, Brooks JHM, Cancea RJ, et al. Contact events in rugby union and their propensity to cause injury. $\mathrm{Br} J$ Sports Med 2007;41:862-7.

14. IRB. Laws of the Game. Dublin: International Rugby Board, 2013.

15. Iwamoto J, Abe H, Tsukimura $\mathrm{Y}$, et al. Relationship between radiographic abnormalities of lumbar spine and incidence of low back pain in high school rugby players: a prospective study. Scand $J$ Med Sci Sport 2005;15:163-8.

16. Broughton $\mathrm{H}$. Premature degeneration of the cervical spine in a rugby union player. New Zeal J Sport Med 1993:21:48-9.

17. Scher AT. Premature onset of degenerative disease of the cervical spine in rugby players. South African Med J 1990;77:557-8.

18. Castinel BH, Adam P, Milburn PD, et al. Epidemiology of cervical spine abnormalities in asymptomatic adult professional rugby union players using static and dynamic MRI protocols: 2002 to 2006 . $\mathrm{Br} \mathrm{J}$ Sports Med 2010;44:194-9.

19. Berge J, Marque B, Vital JM, et al. Age-related changes in the cervical spines of front-line rugby players. Am J Sports Med 1999;27:422-9.

20. Armour KS, Clatworthy BJ, Bean AR, et al. Spinal injuries in New Zealand rugby and rugby league: a twenty year survey. $N Z$ Med $J$ 1997;110:462-5.

21. Bohu $\mathrm{Y}$, Julia M, Bagate C, et al. Declining incidence of catastrophic cervical spine injuries in French rugby: 1996-2006. Am J Sports Med 2009;37:319-23.

22. Dunn RN, van der Spuy D. Rugby and cervical spine injuries-has anything changed? A 5-year review in the Western Cape. South African Med J 2010;100:235-8.

23. Secin FP, Poggi EJ, Luzuriaga F, et al. Disabling injuries of the cervical spine in Argentine rugby over the last 20 years. $B r J$ Sports Med 1999;33:33-6.

24. Wetzler MJ, Akpata T, Albert T, et al. A retrospective study of cervical spine injuries in American rugby, 1970 to 1994. Am J Sports Med 1996:24:454-8.

25. Wetzler MJ, Akpata T, Laughlin W, et al. Occurrence of Cervical Spine Injuries during the Rugby Scrum. Am J Sports Med 1998:26:177-80.

26. Brooks JH, Fuller CW, Kemp SP, et al. Epidemiology of injuries in English professional rugby union: part 1 match injuries. $\mathrm{Br} J$ Sports Med 2005;39:757-66.
27. Milburn PD. The kinetics of rugby union scrummaging. J Sports Sci 1990;8:47-60.

28. Quarrie KL, Wilson BD. Force production in the rugby union scrum $J$ Sports Sci 2000;18:237-46.

29. Preatoni E, Stokes KA, England ME, et al. The influence of playing level on the biomechanical demands experienced by rugby union forwards during machine scrummaging. Scand J Med Sci Sport 2013;23:e178-84.

30. Du Toit DE, Olivier PE, Buys FJ. Kinetics of full scrum and staggered scrum engagement in under 19 schoolboy rugby union players. S Afr J Res Sport Phys Educ Recreat 2005;27:15-28.

31. Cazzola D, Preatoni E, Stokes KA, et al. A modified prebind engagement process reduces biomechanical loading on front row players during scrummaging: a cross-sectional study of 11 elite teams. Br J Sports Med 2015;49:541-6.

32. Cazzola D, Stone B, Holsgrove TP, et al. Spinal muscle activity in simulated rugby union scrummaging is affected by different engagement conditions. Scand J Med Sci Sports 2015. doi:10.1111/ sms. 12446

33. Flavell CA, Sayers MG, Gordon SJ, et al. Mechanisms for triceps surae injury in high performance front row rugby union players: a kinematic analysis of scrummaging drills. J Sport Sci Med 2013;12:159-64.

34. Sayers M, Reilly T, Korkusuz F. Kinematic analysis of high-performance rugby props during scrum training. The Proceedings of the Sixth World Congress on Science and Football. Abingdon, Oxon, U K: Routledge, 2009.

35. Williams JM, Haq I, Lee RY. A novel approach to the clinical evaluation of differential kinematics of the lumbar spine. Man Ther 2013;18:130-5.

36. Wong WY, Wong MS. Trunk posture monitoring with inertial sensors. Eur Spine J 2008;17:743-53.

37. Swaminathan R, Williams JM, Jones MD, et al. A kinematic analysis of the spine during rugby scrummaging on natural and synthetic turfs. J Sports Sci 2015;1-9. doi:10.1080/02640414.2015.1088165

38. Netto KJ, Burnett AF, Coleman JL. Neck exercises compared to muscle activation during aerial combat maneuvers. Aviat Space Environ Med 2007;78:478-84.

39. Burnett A, Green J, Netto K, et al. Examination of EMG normalisation methods for the study of the posterior and posterolateral neck muscles in healthy controls. J Electromyogr Kinesiol 2007;17:635-41.

40. Basmaijan JV. Muscles Alive. Their Functions Revealed by Electromyography. 4th edn. Baltimore: The Williams \& Wilkins Company, 1978:83-91

41. Sommerich CM, Joines SM, Hermans V, et al. Use of surface electromyography to estimate neck muscle activity. J Electromyogr Kinesiol 2000;10:377-98.

42. Lee RY, Laprade J, Fung EH. A real-time gyroscopic system for three-dimensional measurement of lumbar spine motion. Med Eng Phys 2003:25:817-24.

43. Cholewicki J, Silfies SP, Shah RA, et al. Delayed trunk muscle reflex responses increase the risk of low back injuries. Spine (Phila Pa 1976) 2005;30:2614-20.

44. Dankaerts W, O'Sullivan P, Burnett A, et al. Altered patterns of superficial trunk muscle activation during sitting in nonspecific chronic low back pain patients: importance of subclassification. Spine (Phila Pa 1976) 2006;31:2017-23.

45. Wade M, Campbell A, Smith A, et al. Investigation of spinal posture signatures and ground reaction forces during landing in elite female gymnasts. J Appl Biomech 2012;28:677-86.

46. Chosa E, Totoribe K, Tajima N. A biomechanical study of lumbar spondylolysis based on a three-dimensional finite element method. $J$ Orthop Res 2004;22:158-63.

47. Fioretti S. Signal processing in movement analysis (a state-space approach). Hum Mov Sci 1996;15:389-410.

48. Cazzola D, Preatoni E, Stokes K, et al. Does a Modified Rugby Scrum Engagement Process Improve the Stability of the Scrum and Minimise the Likelihood of Scrum Collapse? Br J Sports Med 2014:48:577-8.

49. Preatoni E, Stokes KA, England ME, et al. Engagement techniques and playing level impact the biomechanical demands on rugby forwards during machine-based scrummaging. Br J Sports Med 2015;49:520-8.

50. Cazzola D, Preatoni E, Stokes K, et al. The Effect of a Pre-Bind Engagement Technique on the Biomechanical Characteristics of Rugby Scrummaging Across Multiple Playing Levels. Br J Sports Med 2014:48:578.

51. Kuster D, Gibson A, Abboud R, et al. Mechanisms of cervical spine injury in rugby union: a systematic review of the literature. $\mathrm{Br} \mathrm{J}$ Sports Med 2012;46:550-4. 
52. Kumaresan S, Yoganandan N, Pintar FA. Finite element analysis of the cervical spine: a material property sensitivity study. Clin Biomech 1999;14:41-53.

53. Adams MA, Hutton WC. The effect of posture on the lumbar spine. J Bone Jt Surg Br 1985;67:625-9.

54. Skrzypiec D, Pollintine P, Przybyla A, et al. The internal mechanical properties of cervical intervertebral discs as revealed by stress profilometry. Spine (Phila Pa 1976) 2007;16:1701-9.

55. Olson MW, Li L, Solomonow M. Flexion-relaxation response to cyclic lumbar flexion. Clin Biomech (Bristol, Avon) 2004;19:769-76.

56. McGill SM, Hughson RL, Parks K. Changes in lumbar lordosis modify the role of the extensor muscles. Clin Biomech (Bristol, Avon) 2000; $15: 777-80$.
57. Goel VK, Kong W, Han JS, et al. A combined finite element and optimization investigation of lumbar spine mechanics with and without muscles. Spine (Phila Pa 1976) 1993;18:

$$
\text { 1531-41. }
$$

58. Burnett A, O'Sullivan $\mathrm{P}$, Ankarberg $\mathrm{L}$, et al. Lower lumbar spine axial rotation is reduced in end-range sagittal postures when compared to a neutral spine posture. Man Ther 2008;13:300-6.

59. Ebert R, Campbell A, Kemp-Smith K, et al. Lumbar spine side bending is reduced in end range extension compared to neutral and end range flexion postures. Man Ther 2014;19:114-18.

60. Cholewicki J, McGill SM. Mechanical stability of the in vivo lumbar spine: implications for injury and chronic low back pain. Clin Biomech (Bristol, Avon) 1996;11:1-15. 